\title{
Yerel Zemin Özelliklerinin Microtremor ve ÇKYD Yöntemlerinden Elde Edilen Parametreler Kullanılarak İrdelenmesi: Eğridere/İzmir Örneği
}

\author{
Examination of Local Soil Properties Using Parameters \\ Obtained From Microtremor and Masw Methods: Eğridere / \\ Izmir Case Study
}

\author{
Aykut Tunçel $1^{*}$ (1) \\ ${ }^{1}$ Dokuz Eylül Üniversitesi Mühendislik Fakültesi Jeofizik Mühendisliği Bölümü, İzmir, TÜRKIYE \\ Sorumlu Yazar / Corresponding Author*: aykut.tuncel@deu.edu.tr \\ Geliş Tarihi / Received: 21.04.2021 Araştırma Makalesi/Research Article \\ Kabul Tarihi / Accepted: 19.09.2021 DOI:10.21205/deufmd.2022247006 \\ Atıfsekli/How to cite: TUNÇEL, A.(2022). Yerel Zemin Özelliklerinin Microtremor ve ÇKYD Yöntemlerinden Elde Edilen Parametreler \\ Kullanılarak İrdelenmesi: Eğridere/İzmir Örneği. DEUFMD, 24(70), 45-54.
}

Öz

Eğridere inceleme alanı yüksek kotlarda ve dayanımı yüksek jeolojik birimler üzerinde yer almasına rağmen eğimli bir bölge olması ve heyelan potansiyeli yüksek olması sebebiyle risk oluşturabilecek unsurlar barındırmaktadır. Son olarak 2020 yılında Sisam adası yakınlarında yașanan depremde Eğridere mahallesinin yer aldı̆̆ Bornova ilçesi ve çok yakınında olan Bayraklı ilçesinde ciddi derecede yapı hasarı ve can kaybı oluşmuştur. Tüm bu olumsuzlukların etkilediği inceleme alanında 15 noktada mikrotremor ve aynı noktaların üzerinde 15 profilde çok kanallı yüzey dalgaları yöntemleri kullanılarak veri toplanmıștır. Tek istasyon mikrotremor yöntemi ile toplanan verilerin, yatay düşey spektral oran tekniği ile değerlendirilmesiyle, zemin hâkim titreşim frekansı, büyütme faktörü ve zafiyet indeksi parametreleri hesaplanmıștır. Diğer bir yöntem olan çok kanallı yüzey dalgaları yöntemi kullanılarak toplanan verilerin değerlendirilmesiyle 30 metreye kadar olan kayma dalgası hızı elde edilmiștir ve bu hız kullanılarak zemin büyütmesi, zemin hakim titreșim frekansı ve zemin sınıfı parametreleri hesaplanmıştır. İnceleme alanındaki kayma dalgası hızlarının genelde 500 $\mathrm{m} / \mathrm{sn}$ 'den daha düșük olmadığı her iki yöntemden elde edilen frekans değerlerinin ise çoğunlukla 4$7 \mathrm{~Hz}$ arasında elde edildiği gözlenmiștir. Tüm elde edilen parametrelerin alandaki dağılım haritaları hazırlanmış ve bu parametrelerin jeolojik birimlerle ilişkisi kurularak çalışma alanının zemin özellikleri hakkında sonuçlar ortaya konulmaya çalıșılmıștır. Deprem ve diğer risklere karșı dayanıklılık gösterebilecek zemin parametrelerinin çalıșma alanında yaygın olmasına rağmen, değişken kot ve jeoloji sunması sebebiyle parsel bazında ayrıntılı çalışmalar gerektiren bir bölge olduğu sonucu çıkmaktadır. Bunun yanı sıra bölgede heyelan riski de göz önüne alınmalıdır.

Anahtar Kelimeler: Bornova, Eğridere, mikrotremor, ÇKYD, zemin özellikleri

\section{Abstract}

Although the Eğridere study area is located at high elevations and on geological units with high strength, it contains elements that may pose a risk due to its inclination and high landslide potential. In the recent earthquake that occurred near Samos island in 2020, serious building damage and loss 
DEÜ FMD 24(70), 45-54, 2022

of life occurred in Bornova district, where Eğridere district is located and in Bayraklı district, which is very close. In the study area affected by all these negativities, data were collected using microtremor at 15 points and multi-channel surface waves in 15 profiles above the same points. By evaluating the data collected by single station microtremor method with horizontal to vertical spectral ratio technique, soil predominant frequency, amplification factor and vulnerability index parameters were calculated. Shear wave velocity up to 30 meters was obtained by evaluating the data collected by using another method, the multi-channel surface waves method, and using this velocity, soil amplification, soil predominant frequency and site classification parameters were calculated. It was observed that the shear wave velocities in the study area are generally not lower than $500 \mathrm{~m} / \mathrm{sec}$, and the frequency values obtained from both methods are mostly between 4-7 Hz.The distribution maps of all the obtained parameters in the area were prepared and by establishing the relationship of these parameters with the geological units, the results about the soil properties of the study area were tried to be revealed. Although soil parameters that can resist earthquakes and other risks are common in the study area, it is concluded that it is a region that requires detailed studies on parcel basis due to its variable elevation and geology. In addition, the risk of landslides in the region should also be considered.

Keywords: Bornova, Eğridere, microtremor, MASW, soil properties

\section{Giriş}

Bilindiği üzere deprem hareketi bir doğa olayıdır ve meydana gelmesi önlenebilen bir hareket değildir. Bu sebeple depremin oluşturabileceği can ve mal kayıplarından korunmak için önlemler almak gerekmektedir. Korunma önlemlerinin başında depreme dayanıklı yapılar içinde ikamet etmek ilk akla gelir. Depreme dayanıklı bir yapının büyük magnitüdlü depremlerde can güvenliğini sağlaması ve kalıcı yapısal hasar almaması gerekir. Deprem dalgalarının yapıya temas ettiği yer zemindir. Dolayısıyla dayanıklı ve güvenli yapılar tasarlamak için binanın oturacağı zemin ve fiziksel özellikleri net olarak tanımlanmalıdır. Ana kayanın derinliği, kayma dalgası hızı (Vs), zemin hakim titreșim periyodu $\left(\mathrm{T}_{0}\right)$ ve zemin büyütmesi (A) değerlerinin elde edilmesi gerekli olan başlıca parametreler olarak tanımlanabilir [1]. Depremin kaynağından yola çıkan sismik dalgalar yapıya en son zemin tabakasından geçerek ulaşırlar ve zemin tabakasının fiziksel özellikleri ölçüsünde binaya etkirler.

Günümüzde Türkiye Bina Deprem Yönetmeliği [2], Eurocode 8 [3] ve NEHRP [4] yönetmelikleri dünya çapında en çok kullanılan yönetmeliklerdir. $\mathrm{Bu}$ yönetmeliklerde zeminlerin dinamik koșullardaki davranıșlarının ön kestirilmesinde üst 30 metredeki kayma dalgası hız değerleri $\left(\mathrm{V}_{\mathrm{S} 30}\right)$ ve zemin hakim titreşim frekansı (ZHTF) değerleri yaygın olarak kullanılır. Ayrıca yerel zemin sinıflarının belirlenmesinde kayma dalgası hızı $\mathrm{V}_{\mathrm{S}}$ ve SPT darbe sayısı N kullanılabilir. Jeofizik yöntemlerle elde edilen parametrelerin mikro bölgeleme çalışmalarında kullanımı Uyanık [5] tarafından ayrıntılı olarak tartışılmıştır.

Birinci derece deprem bölgesinde yer alan İzmir şehri yıkıcı depremlerden etkilenmektedir. Sisam Adası'nın hemen kuzeyinde ülkemiz sınırları içinde çalıșma alanına $75 \mathrm{~km}$ uzaklıkta büyüklüğü $\mathrm{Mw}$ 6,6 derinliği 14,9 km olan bir deprem meydana gelmiștir [6]. Çalıșma alanına çok yakın olan Bornova ve Bayraklı ilçeleri 30 Ekim 2020 tarihinde meydana gelen depremden ağır şekilde etkilenerek çok büyük can kaybı ve maddi hasara uğramıştır. Yapılan değerlendirmeler sonucunda; 30 Ekim 2020 depreminin Sisam Fayı üzerinde yaklaşık $30 \mathrm{~km}$ uzunlukta bir kırılmaya yol açtığ düșünülmektedir [6]. Nüfus artıșı, yüksek katlı yapılaşma ve zeminin dinamik parametrelerinin titizlikle hesaplanmadığı durumlarda deprem riski artmaktadır. Zemin ve bina parametrelerinin mühendislik çalışmalarıyla düzgün ve güvenilir şekilde hesaplanması durumunda, deprem sonucunda meydana gelecek olan sosyo-ekonomik hasarlar en aza inebilir.

$\mathrm{Bu}$ çalışma kapsamında, İzmir ilinin kuzeyinde yer alan, depremde çok sayıda can kaybı ve yapı hasarına maruz kalan Bornova ilçesinin hemen üst kotlarında bulunan Eğridere mahallesinde jeofizik yöntemler ile veri toplanmıştır (Şekil 1). Mikrotremor ve çok kanallı yüzey dalgaları (ÇKYD) yöntemleri kullanılarak jeolojik 
birimlerin dinamik koşullar altındaki özelliklerinin tanımlanması hedeflenmiştir. Mikrotremor yöntemiyle kaydedilen verilerin değerlendirilmesiyle zemin hakim titreșim frekansı (ZHTF), büyütme faktörü ve zafiyet indeksi $(\mathrm{Kg})$ parametrelerine ulașılmıștır. Hesaplanan tüm parametelerin çalışma alanınki dağılımları haritalar üzerinde gösterilmiş ve bu parametrelerin fiziksel anlamları tartışılarak çalışma alanı yorumlanmıștır. ÇKYD yöntemi ile toplanan verilerin değerlendirilmesi sonucunda 30 m derinliğe kadar olan kayma dalgası hızları (Vs30) elde edilmiștir. $\mathrm{Bu}$ hız değerleri kullanılarak çalıșma alanında ZHTF, zemin büyütmesi değerleri hesaplanmıștır. Ayrıca $V_{\mathrm{S} 30}$ hızları kullanılarak NEHRP [4] yönetmeliğine göre zemin sınıflaması yapılmıştır. ÇKYD yöntemi kullanılarak elde edilen tüm parametreler de dağılım haritaları çizilerek görselleștirilmiştir. Uygulanan jeofizik yöntemlerin sonucunda elde edilen parametrelerin değişimi ve jeolojik birimlerle ilișkisi yorumlanarak bölgenin zemin özellikleri irdelenmiştir. Daha önce benzer birçok çalışma [7-9] Bornova ilçesi için yapılmış ve bu çalışmalardan sonra meydana gelen depremde yoğun hasar ve can kayıplarının zemin özellikleri kötü olan bölgelerde yoğunlaștığı görülmüștür. $\mathrm{Bu}$ kapsamda zemin özelliklerinin belirlenmesini amaçlayan çalışmalar deprem hasarlarını azaltmak için büyük önem taşımaktadır. Zemin özelliklerinin tanımlanması amacıyla ayrıntılı jeofizik çalışmalar yaygın şekilde uygulanmaktadır [10].

\section{2. Çalışma Alanı ve Jeoloji}

Bornova ilçesi, İzmir șehri sınırları içerisinde yer alan büyük ve yoğun nüfusa sahip bir ilçedir. Çalışmanın yapıldığı Eğridere Mahallesi, Bornova ilçe merkezine $4 \mathrm{~km}$ uzaklıkta İzmir şehir merkezinin kuzeydoğusunda yer almaktadır (Şekil 1). Eğridere mahallesi şehir merkezine göre daha yüksek kotlarda konumlanmıș ve genelinde sağlam zemin özelliği gösteren bir bölgedir. Bununla birlikte heyelan potansiyeli yüksek olan bir bölge olduğu bilinmektedir [11]. Eğridere mahallesinde 2019 yılı şubat ayında şiddetli yağış sonrasında büyük bir heyelan meydana gelmiștir ve bu olayda yaklaşık 10 ev ve hayvan barınağı tamamen yıkılmış veya ağır hasar almıștır[12]. Bu sebeple yapılaşma öncesi parsel bazında zemin koșullarının ayrıntılı incelenmesi ve heyelan riskinin de bölgesel olarak araștırılması yerinde olacaktır. Heyelan çalışmaları yürütülürken sismik ve elektrik yöntemler sıklıkla kullanılmakta ve başarılı sonuçlar vermektedir [13-15]. Bu çalışma kapsamında elektrik yöntem kullanılmamış olup ileriki çalıșmalarda ayrıntılı heyelan potansiyeli olan yerlerin belirlenmesi amacıyla çalışmalar genişletilebilir.

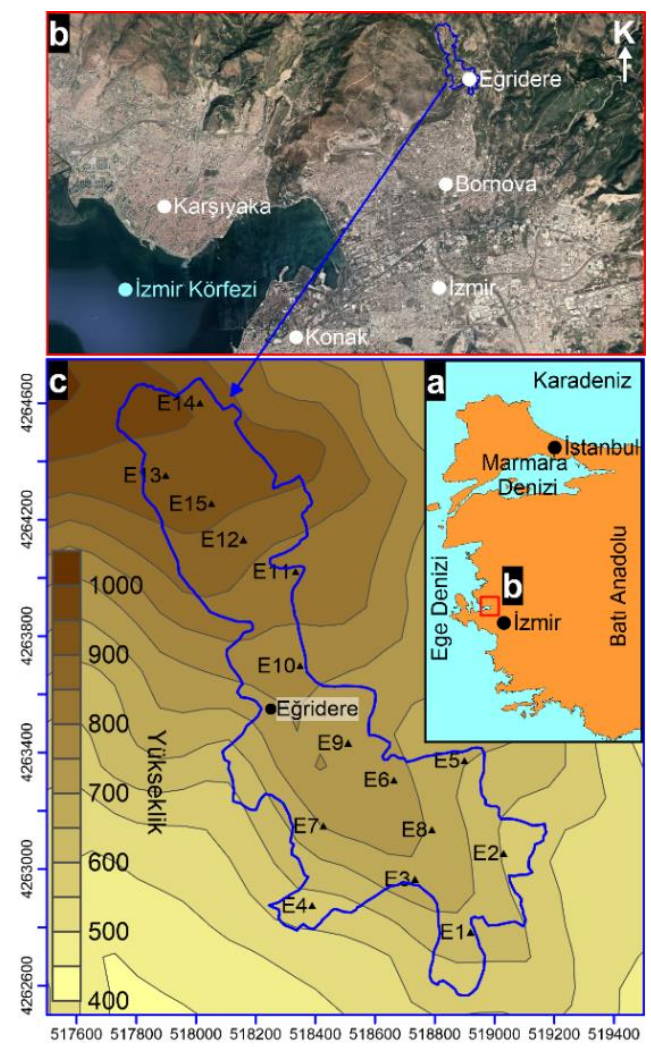

Şekil 1.- Yerbulduru haritası a Batı Anadolu b İzmir körfezi ve Bornova ilçesi c. İnceleme alanının topoğrafik haritası ve ölçüm yapılan jeofizik yöntem noktaları (siyah üçgen).

Çalışma alanı ve çevresinin genel jeolojisine bakıldığında Bornova Melanjı (karmașığı), killi kireçtașı, yamaç molozu ve alüvyon yer almaktadır. Bornova karmaşığı, çakıltaşıkumtaşı-çamurtaşı ardalanmasından oluşmuş, kesikli ve sürekli Bouma istifi sunduğu için paleoakıntılar sonucunda gelișen, türbitidik akıntılarla filiș fasiyesinde çökelmiștir [16]. Bornova melanjı çalışma alanındaki en eski birim konumundadır. Neojen yaşlı gölsel tortullar Bornova Melanjı'nın üzerine açısal uyumsuz olarak gelir. Kuvaterner yaşlı Yamaç Molozu ve alüvyon alanda mevcut tüm birimleri 
DEÜ FMD 24(70), 45-54, 2022

uyumsuz olarak üstler [17]. Bornova Melanjı (karmaşığı), kumtaşı/şeyl-kalkerli şeyl ardalanmasından oluşmuş matriks içerisinde yüzen platform türü kireçtaşı ve diyabaz bloklarından ve çakıltaşı mercek/kanal dolgularından meydana gelmiștir [16]. Çalışmanın yapıldı̆̆ı Eğridere mahallesinin genel jeoloji haritasına göre yaygın olarak andezit birimlerin yer aldığı görülmektedir (Şekil 2.a). $\mathrm{Bu}$ andezit birimler çeşitli boy, dayanım ve ayrışma derecesinde olabilirler. Andezitik bileşimde birden fazla volkanik aktivite sonucunda oluşmuş olan volkanitler, tabanda ince bir tüf seviyesiyle başlar, aglomera ve andezit lavlarıyla devam eden kalın bir istif sunar. En üstte, bahsedilen birimlerden türeme, onların çakıl ve bloklarını içeren, ayrışma ürünü kil, silt ve kum boyutunda zemin türü malzemeden oluşan alüvyon ve yamaç molozları bulunmaktadır (Şekil 2.b). Bornova ve civarında yaygın olarak gözlenen yamaç molozu, üstlediği birimin ayrışmasıyla oluşmuştur. Yamaç molozu Bornova Karmașığına ait birimleri ve tamamen andezitik lav akmalarının ayrışmasına ait birkaç santimetreden birkaç metreye kadar değișen boyutlarda bloklar içermektedir [18].

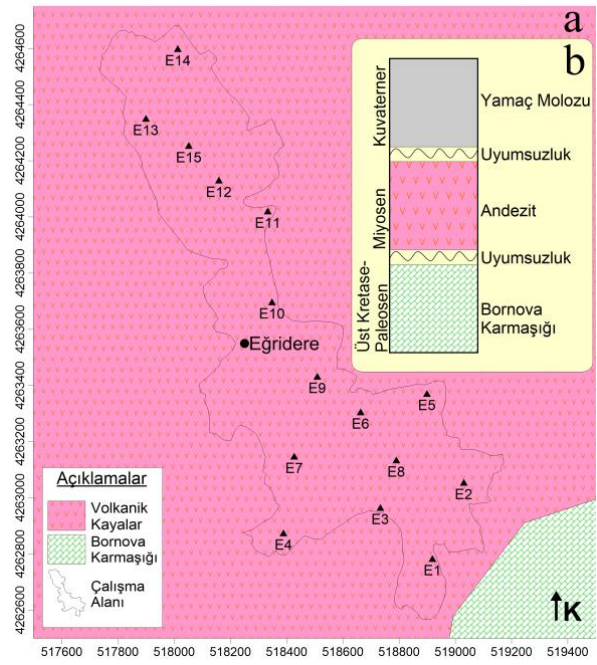

Şekil 2.a Genel jeoloji haritası b Stratigrafik kolon kesit.

\section{Mikrotremor Yöntemi Uygulama ve Değerlendirme}

Bölgesel tarama amaçlı jeofizik etütlerde yaygın ve başarılı bir şekilde uygulanan mikrotremor yöntemi çalıșma alanında 15 noktada tatbik edilmiştir. $\mathrm{Bu}$ noktaların arası 200-300 metre mesafe olacak şekilde çalışma alanında yayılmaktadır. Aynı noktalarda ÇKYD ölçümleri de bir hat boyunca uygulanmıștır. Çalışma kapsamında Sara SR04 markalı 3 bileșenli hızölçer bir sismometre kullanılarak veriler kaydedilmiştir. Cihaz yere terazide olacak şekilde özenle yerleştirilerek $30 \mathrm{dk}$ kayıt süresi olacak şekilde veri toplanmıştır. Kayıt sırasında örnekleme aralığı $100 \mathrm{~Hz}$ olacak şekilde kayıtçı ayarlanmıștır.

Ölçümler Nakamura [19] tek istasyon tekniği esas alınarak değerlendirilmiștir. Değerlendirme aşamalarında öncelikle mikrotremor verilerinin trend etkisi giderilmiştir. Trend etkisinden arındırılan veriye $0,1-20 \mathrm{~Hz}$ aralığında bant geçişli süzgeç uygulanmıștır. Daha sonra 20,48 sn. ve 40,96 sn. pencere boyları ve kosinüs pencere tipi seçilerek veri törpülenmiştir. Yuvarlatma için Konno-Ohmachi [20] tipi ve yuvarlatma sabiti 30 seçilmiştir. Her bir pencere için Hızlı Fourier Dönüşümü (FFT) uygulanarak her bir bileșene ait genlik spektrumları elde edilmiștir. Nihai hedef olan yatay düșey spektral oran (HVSR) değerleri yatay bileşen spektrumlarının düşey bileșen spektrumuna oranlanmasıyla elde edilmiștir.

Kaydedilen verilerin değerlendirilmesi sonucunda HVSR spektrum grafiği elde edilmiş ve elde edilen bu grafikten ZHTF değerleri okunmuştur. Çalışma alanında elde edilen hakim frekans değerlerinin bölgeye dağılımı kontur haritası üzerinde Şekil 3'de gösterilmiştir.

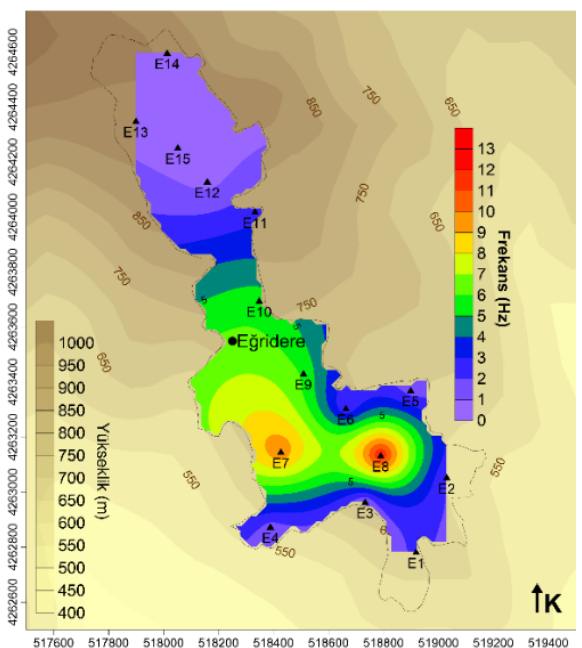


DEÜ FMD 24(70), 45-54, 2022

Şekil 3. Mikrotremor yönteminden hesaplanan ZHTF değerlerinin çalışma alanında dağılımı (topoğrafya haritası üzerine çizilmiştir).

Hakim frekansa karşıllk gelen büyütme faktörü değerleri de spektrum grafiğinden okunarak haritalanmıştır (Şekil 4). Büyütme faktörü değerleri genelde 2 ile 3 arasında değişim göstermekle birlikte çalışma alanının güneyinde 5 değeri civarına ulaşmaktadır. Büyütme faktörü değerinin 2'den büyük olması SESAME [21] projesinde tavsiye edilen değerlendirme kriterlerini sağlaması açısından önemlidir.

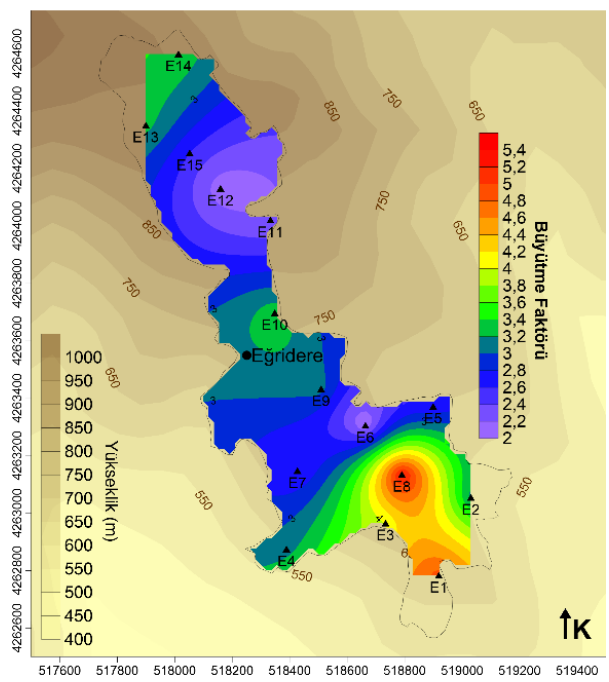

Şekil 4. Çalışma alanında hesaplanan büyütme faktörü değerlerinin dağılım haritası.

$\mathrm{Bu}$ çalışmada zemin $\mathrm{Kg}$ değerleri hesaplanmış olup, $\mathrm{Kg}$ değerinin matematiksel hesabı Nakamura [22] çalışmasında en net şekilde açıklanmış ve bağıntı 1'de verilmiştir.

$$
K g=\mathrm{Ag}^{2} / F g
$$

Bağıntıda Ag en büyük genlik değeri yani büyütme faktörüdür, Fg ise Ag'ye karşılık gelen frekans değerini yani ZHTF olarak bahsedilen frekansı temsil eder. Kg değeri ile deprem sonrasında oluşan yapısal hasarlar arasındaki ilişki Nakamura [23] tarafından incelenmiş ve hasar oranının arttığ yerlerde zafiyet indeksinin 20 den büyük değerler aldığı ortaya konulmuştur. Zemin zafiyet indeksi olarak tanımlanan Kg değerlerinin, inceleme alanında en çok 20 değerine kadar yükseldiği görülmektedir (Şekil 5). Bu parametrenin hesaplanmasıyla çalıșma alanındaki tehlikeli bölgeler belirlenebilir ve depremden önce hasarın oluşabileceği alanlar tahmin edilebilir.

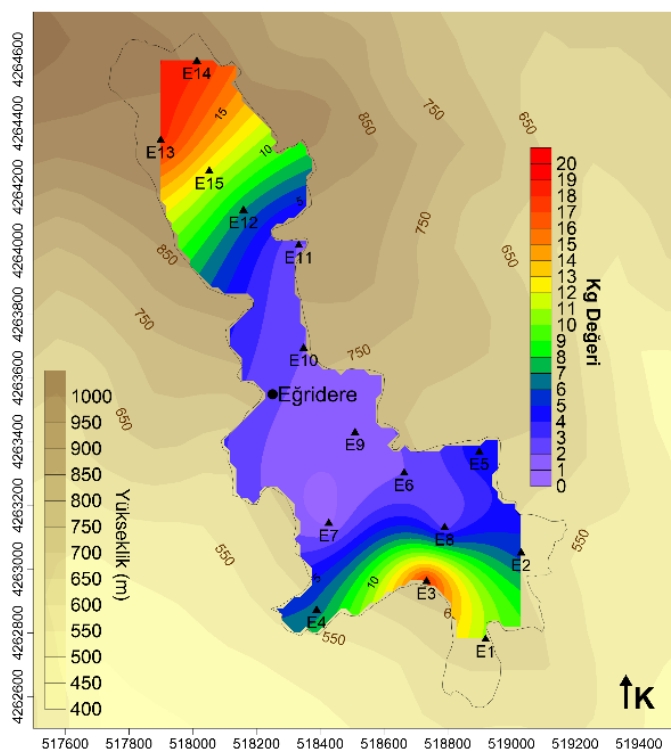

Şekil 5. Zemin zafiyet indeksi (Kg) değerlerinin çalışma alanını topoğrafya haritası üzerindeki dağılımı.

\section{CKYD Yöntemi Uygulama ve Değerlendirme}

CKYD yöntemi arazi çalısmaları 15 serimde yapılmıştır. Serim uzunlukları $72 \mathrm{~m}$ ve offset mesafesi $6 \mathrm{~m}$ olacak sekilde arazi konumlanmaları ayarlanmıș ve yöntem uygulanmıştır. Jeofon aralıkları ise $3 \mathrm{~m}$ olacak șekilde hazırlanmıș ve güç kaynağı olarak $10 \mathrm{~kg}$ ağırlığında balyoz kullanılmıștır. Yöntem çalıșma alanında Rusya üretimi Lakkolit X-M3 markalı sismik cihaz kullanılarak yürütülmüştür. Sismik yöntemin uygulandığı cihaz 24 kanallı olarak çalıșmaktadır, bu cihazla birlikte $4,5 \mathrm{~Hz}$ düșey bileșenli jeofonlar kullanılmıștır. Her atış noktasında en az 3 kez vuruş yapılarak kayıtlar alınmıştır. Kullanılan ekipman ve arazide ölçü alma dizilimine ait görüntüler Şekil 6'da verilmiștir. 
DEÜ FMD 24(70), 45-54, 2022

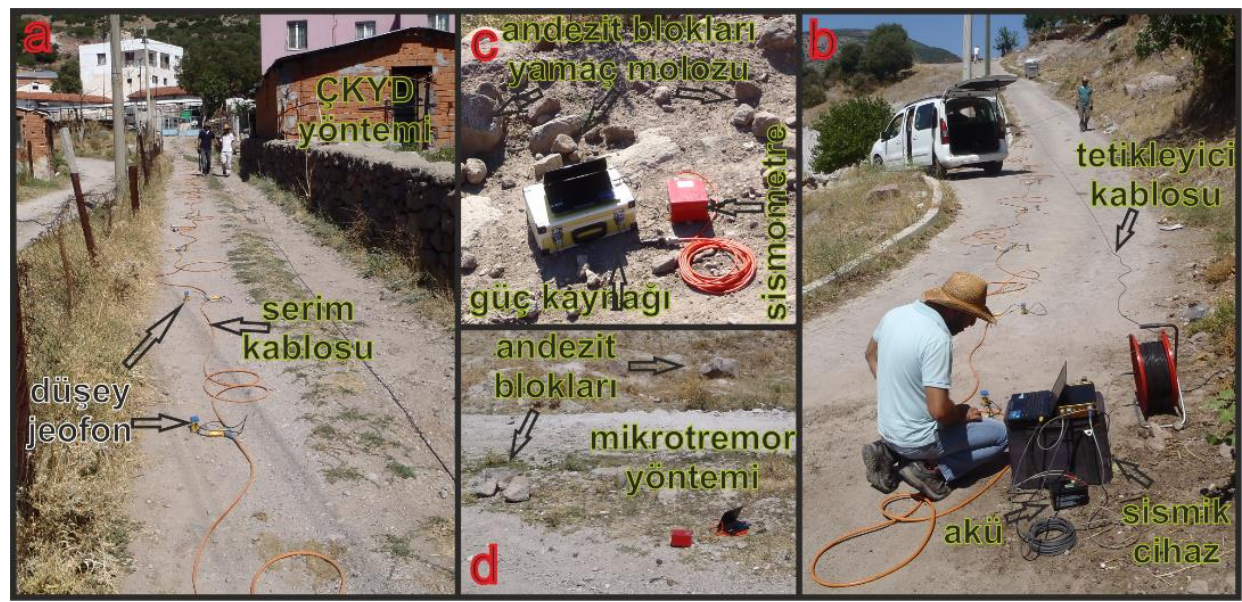

Şekil 6.a,b ÇKYD yönteminin arazide uygulanması ve kullanılan ekipman c,d mikrotremor yönteminde kullanılan cihaz ve arazide yerleşimi.

Çalışma alanında kaydedilen veriler SeisImager yazılımı kullanılarak değerlendirilmiștir. Faz hızının frekansa bağlı olarak değișimini gösteren dispersiyon eğrileri elde edilmiştir. Dispersiyon eğrisinde temel modlar ters çözüme sokularak kayma dalgası hızları hesaplanmıștır. İnceleme alanında kayma dalgası hızları $400 \mathrm{~m} / \mathrm{sn}$ ile $1000 \mathrm{~m} / \mathrm{sn}$ arasında hesaplanmıș ve bu hızların dağılım haritası Şekil 7'de verilmiştir. Hesaplanan kayma dalgası hızları 30 metre derinliğe kadar olan ortalama hızlardır ve $\mathrm{V}_{S 30}$ olarak tanımlanmaktadır.

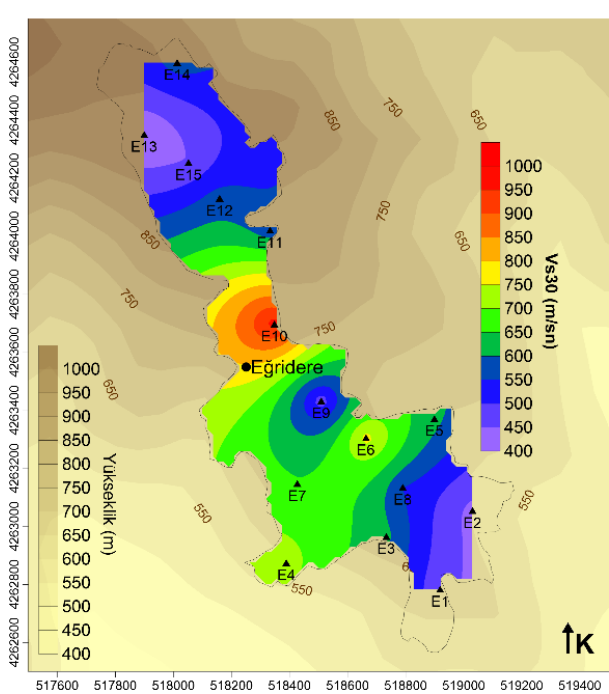

Şekil 7. ÇKYD yöntemiyle hesaplanan $V_{S 30}$ kayma dalgası hızlarının inceleme alanındaki kontur dağılımı.
Birçok araştırmacı [24-26], 30 m'ye kadar ortalama kayma dalgası hizlarını ( $\left.\mathrm{V}_{\text {S30 }}\right)$ kullanarak zemin büyütmesi (A) hesaplanmasını içeren çalışmalar yapmışlar ve sonuç olarak bir formül önermişlerdir ( Tablo 1). Bu çalışmada, Midorikawa'nın [25] korelasyonu kullanılarak zemin büyütmesi değerleri hesaplanmıștır. Çalışma alanında gözlenen en büyük zemin büyütmesi 1,9 değeri olarak hesaplanmış olup 1,1 değerine kadar düşüşlerin olduğu dağılım haritasında görülmektedir (Şekil 8).

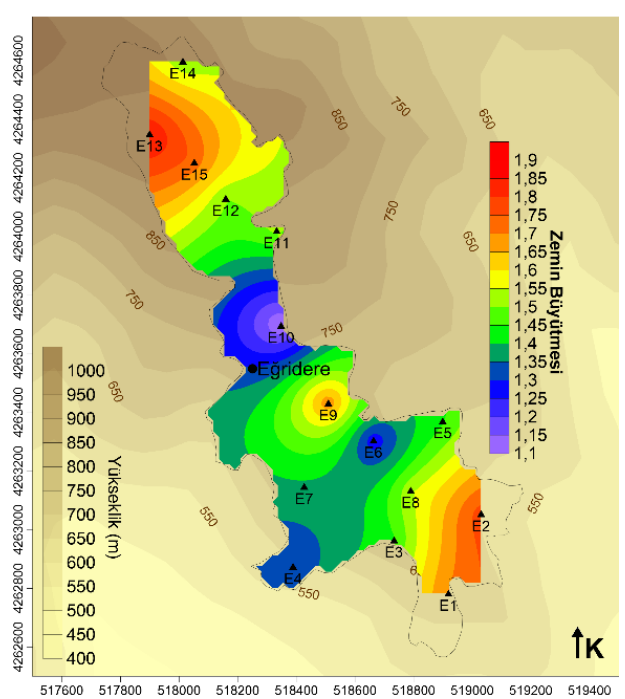

Şekil 8. Elde edilen $V_{S 30}$ kayma dalgası hızı değerleri kullanılarak Midorikawa (1987) [25] bağıntısından hesaplanan zemin büyütmesi değerlerinin inceleme alanındaki dağılımı. 
DEÜ FMD 24(70), 45-54, 2022

Tablo 1. Çeşitli yazarlar tarafından önerilen zemin büyütmesi (A) hesaplama formülleri.

\begin{tabular}{lc}
\hline Yazarlar & Zemin Büyütmesi (A) \\
\hline & $A=68 V_{S 30}^{0,6}$ \\
Midorikawa (1987) [25] & $A=23 V_{S 30}^{0,45}$ \\
Joyner ve Fumal (1984) [24] & $A=\frac{700}{V_{S 30}}$ \\
Borcherdt (1994)-(zayıf hareket) [26] & $A=\frac{600}{V_{S 30}}$ \\
Borcherdt (1994)-(kuvvetli hareket) [26] & \\
\hline
\end{tabular}

Sismik çalışmalarla elde edilen ZHTF değerleri ile deprem kuvvetkerinin zeminde oluşturacağ hakim frekanslar hakkında önceden bilgi edinilebilir. Ortalama kayma dalgası hızı kullanılarak zemin hâkim titreşim frekansı;

$$
Z H T F=\mathrm{VS} 30 / 4 h
$$

bağıntısıyla [27] $30 \quad \mathrm{~m}$ derinliğe kadar hesaplanmıș ve alanın ZHTF dağılım haritası oluşturulmuştur (Şekil 9) Zeminin sadece kalınlığı ile Vs hızına bağımlı olan ZHTF, en önemli büyütmenin hangi titreșim frekansında gerçekleșebileceği hakkında çok önemli bir belirteçtir [28]. İnceleme alanında elde edilen $\mathrm{V}_{\text {S30 }}$ kayma dalgası hızı değerleri, Ulusal Deprem Tehlikelerini Azaltma Programina (NEHRP) [4] göre zemin sınıflarının belirlenmesi için kullanılmıștır. Makaslama dalgası hızlarının 30 m’ye kadar aldığı değerlere göre tablodaki isimlendirmeler kullanılarak zeminler sınıflandırılmıştır (Tablo 2). Tabloya göre en sağlam zemin sınıfı A olacak şekilde, dayanım azaldıkça ise $\mathrm{F}$ harfine doğru değişen şekilde düzenlenmiștir.

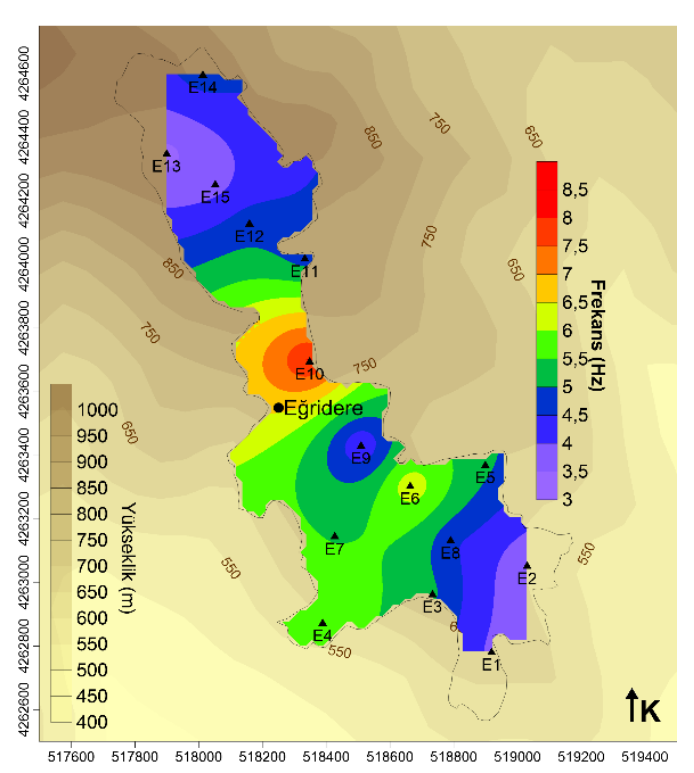

Şekil 9. Kayma dalgası hızı kullanılarak hesaplanan ZHTF değerlerinin çalışma alanındaki değişimi.

Tablo 2. Kayma dalgası hızlarına göre NEHRP [4] zemin sınıflama tablosu.

\begin{tabular}{lll}
\hline \multirow{2}{*}{ Zemin Sınıfı } & Zemin Tanımlaması & Makaslama Dalgası Hızı (V V30 \\
\hline A & Sert ana kaya & $>1500 \mathrm{~m} / \mathrm{s}$ \\
B & Sağlam, dayanıklı ile sert kaya arası birimler & $760-1500 \mathrm{~m} / \mathrm{s}$ \\
C & Yoğun toprak, yumuşak kaya & $360-760 \mathrm{~m} / \mathrm{s}$ \\
D & Sert toprak & $180-360 \mathrm{~m} / \mathrm{s}$ \\
E & Yumuşak killer & $<180 \mathrm{~m} / \mathrm{s}$ \\
F & Özel çalışma gerektiren zeminler & \\
\hline
\end{tabular}


DEÜ FMD 24(70), 45-54, 2022

Çalışma alanında zemin sınıflaması değișimine bakıldığında, alanın büyük bölümü $\mathrm{C}$ zemin sınıfına girmektedir. Çalışma alanının orta bölümünde ise B sınıfı zemin gözlenen bir bölge yer almaktadır (Şekil 10).

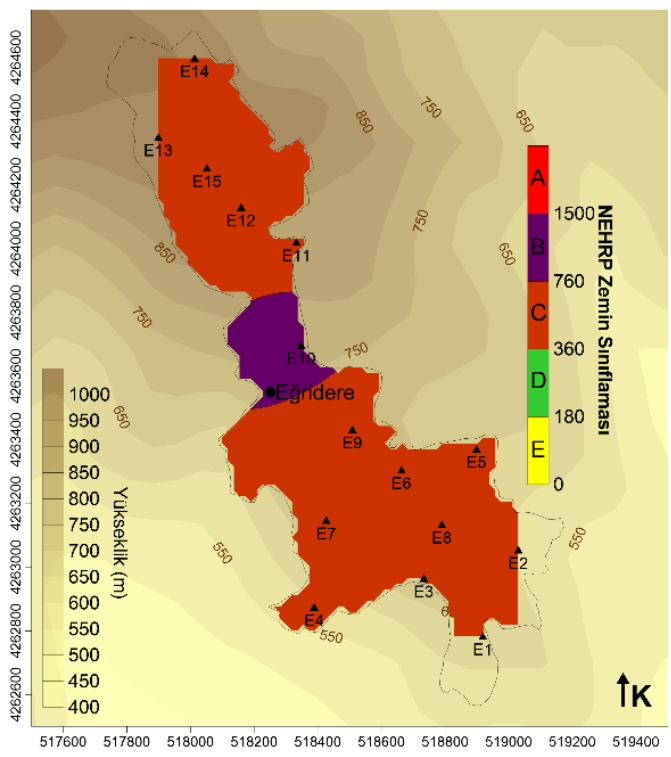

Şekil 10. Kayma dalgası hızları kullanılarak oluşturulan NEHRP zemin sınıflaması haritası.

\section{Tartışma ve Sonuçlar}

İnceleme alanında uygulanan her iki jeofizik yöntemle de elde edilen ZHTF değerleri kendi içinde uyum göstermektedir. Genel olarak kuzey ve güneyde düşük, inceleme alanının orta bölümlerinde ise görece yüksek hakim frekanslar saptanmıștır. Yöntemlerin sonuçları uyumlu olsa da rakamsal olarak farklılıklar gözlenmektedir. Daha önceki çalıșmalarda [29] da bu rakamsal farklılıklarla karşılaşıldığı için beklenen bir durum olarak açıklanabilir. Buna sebep olarak farklı araștırma derinliğine sahip 2 farklı yöntemin karşılaştırılıyor olması da gösterilebilir. Mikrotremor yöntemi genelde daha derinlerden gelen bilgiyi tașırken sismik yöntemle elde edilen hız bilgisi sadece 30 metrelik derinliğe kadar olan ortalama değerdir. Yine zemin büyütmesi değerlerinin de bölgedeki hakim frekans değerleri değișimiyle uyumlu olacak șekilde dağılım gösterdiği söylenebilir. Sismik hızlardan hesaplanan zemin büyütmesi parametresi en büyük değerleri hakim frekansların en düșük olduğu noktalarda almıştır. Büyütme faktörü değerleri ise inceleme alanının en güneyinde yüksek değerler almıştır. Büyütme faktörü değerleri çoğu zaman zemin büyütmesiyle uyumlu sonuçlar vermemekte ve zemin büyütmesi olarak tanımlanmamaktadır.

Kg zafiyet endeksi parametresi çalıșma alanının özellikle kuzey kısımlarında en yüksek değerleri almıștır. Daha önce 2019 yılında meydana gelen heyelanın [12] da bölgenin kuzeyinde olduğu düşünülürse, Eğridere mahallesinin en riskli bölgesinin kuzey yamaçlar olduğu söylenebilir. Çalışma alanının güneyinde de benzer yüksek değer gözlenmiş olmasına rağmen bu değerler 20 civarıdır. Bu değerler riskli olmayıp sadece bu inceleme alanı için görece yüksek olarak tanımlanmıştır. Kg parametresinin 20'den daha büyük değerler aldığı zaman çalıșma alanlarının riskli olarak tanımlandığı daha önceki araştırmalarda ortaya konulmuştur [30,31]. İnceleme alanının orta bölümlerinde ise $\mathrm{Kg}$ değeri daha düşük elde edilmiştir. İnceleme alanının genelinde deprem sonrasında zafiyet gösterecek ve risk oluşacak bir bölge gözlemlenmemekle birlikte yine de yapıların durumu önemlidir. Bölgenin köy yeri olması ve hayvancılık yapılması sebebiyle burada yer alan ve mühendislik hizmeti alınmadan inşa edilmiş ahır ve baraka tipi yapılar risk altında olabilir.

İnceleme alanındaki kayma dalgası hızı dağılımlarında $400 \mathrm{~m} / \mathrm{s}$ ile $1000 \mathrm{~m} / \mathrm{s}$ arası değişimler gözlenmektedir, en yüksek değerleri ise çalışma alanının orta bölümünde $750 \mathrm{~m}$ kot değerine denk gelen bölgede gözlemlenmiștir. Hız değişimlerinin bölgedeki andezit kayaçların farklı tane boyutlarındaki bileșenlerinden (yamaç molozu) kaynaklandığı şeklinde yorumlanabilir.

Elde edilen tüm parametreler hesaba katılarak inceleme alanı hakkında genel bir yorum yapmak gerekirse; inceleme alanında hakim olarak yer alan granit birimlerin farklı tane boyu ve ayrışma derecesindeki bileșenleri alandaki zemin dinamik parametrelerini belirlemektedir. Buna bağlı olarak derinlerden bilgi taşıyan mikrotremor yöntemi ve buradan elde edilen parametrelerden hesap edilen $\mathrm{Kg}$ değerlerine göre zeminin zafiyet gösterme ihtimali düşük olarak yorumlanmaktadır. Sı ̆̆ araștırma derinliği olan ÇKYD yöntemi ile hesaplanan $\mathrm{V}_{\mathrm{S} 30}$ hızlarına göre ise $400 \mathrm{~m} / \mathrm{sn}$ olan değerlere sahip bölgelerde zafiyet görülebilir ancak burada hızı düșüren yüzeydeki ayrıșmış birimlerin etkisi olduğu tahmin edilmektedir. Sığ derinliklerdeki 


\section{DEÜ FMD 24(70), 45-54, 2022}

küçük tane boylu ve ayrıșmıș birimlerin kazı yoluyla ortadan kaldırılmasıyla çalışma alanı genelinde çok daha sağlam birimlere ulaşılabilecektir. Çalışma alanındaki ani kot değișimleri göz önüne alındığında sık aralıklarla yerinde araștırmalar önerilebilir. Jeolojik birim değișimleri ve heyelan potansiyelini iyi tanımlamak için ise bölgesel gözlem yapılarak jeofizik ve jeoloji araștırmaları yürütülmesi faydalı olacaktır.

\section{Teşekkür}

Yazar mikrotremor ve sismik yöntemlerin ham verisin sağlayan Ege Yer Bilimleri Sondajcılık'a tessekkür eder. Yazar makaleye katkı sağlayan ve geliștiren hakemlere teşekkür eder.

\section{Kaynakça}

[1] Yalçınkaya, E. 2004. Bir boyutlu modeller için zemin büyütmesine etki eden parametrelerin incelenmesi. İstanbul Üniversitesi Mühendislik Fakültesi Yerbilimleri Dergisi, Cilt 17(1), s. 47-56.

[2] Türkiye Bina Deprem Yönetmeliği (TBDY). 2018. T.C İçişleri Bakanlığ Afet ve Acil Durum Yönetimi Başkanlığı, Deprem Dairesi Başkanlığı.

[3] Eurocode 8, 2004. prEN 1998-1 Design of structures for earthquake resistance. Part 1: General rules, seismic actions and rules for buildings.

[4] NEHRP, 2003. NEHRP Recommended Provisions for Seismic Regulations for New Buildings and Other Structures, Part 1: Provisions. Building Seismic Safety Council, Washington, DC, USA.

[5] Uyanık, O. 2015. Deprem Ağır Hasar Alanlarının Önceden Belirlenmesi ve Sehir Planlaması için Makro ve Mikro Bölgelendirmelerin Önemi, Süleyman Demirel Üniversitesi, Fen Bilimleri Enstitüsü Dergisi, Cilt 19(2), s. 24-38. DOI: 10.19113/sdufbed.00543

[6] AFAD Deprem Dairesi Başkanlığı, 2020. 30 Ekim 2020 Ege Denizi, Seferihisar (İzmir) Açıkları (17,26 km) Mw 6.6 Depremine İlişkin Ön Değerlendirme Raporu, AFAD.

[7] Tunçel, A. 2008. Sismik Kırılma Yöntemi Ve Mikrotremör Ölçümlerinden Elde Edilen Dinamik Zemin Parametrelerinin Karssılașturılması, Dokuz Eylül Üniversitesi Fen Bilimleri Enstitüsü Yüksek Lisans Tezi, İzmir.

[8] Eskișar, T., Özyalın, Ș., Kuruoğlu. M.i Yılmaz, H.R. 2013. Microtremor Measurements in the Northern Coast of İzmir Bay, Turkey to Evaluate Site-Specific Characteristics and Fundamental Periods by $\mathrm{H} / \mathrm{V}$ Spectral Ratio Method, Journal of Earth System Science, Cilt 122(1), s. 123-136.

[9] Pamuk, E., Gönenç, T., Özdağ, Ö. C., \& Akgün, M. 2018. 3D Bedrock Structure of Bornova Plain and Its Surroundings (Izmir/Western Turkey), Pure and Applied Geophysics, Cilt 175(1), s. 325-340. DOI: 10.1007/s00024-017-1681-0

[10] Akin, Ö., Sayil, N. 2016. Site characterization using surface wave methods in the Arsin-Trabzon province, NE Turkey. Environmental Earth Science Cilt 75:72. DOI: $10.1007 / \mathrm{s} 12665-015-4840-6$
[11] Akgün, A., Kıncal, C., Pradhan, B. 2012. Application of remote sensing data and GIS for landslide risk assessment as an environmental threat to Izmir city (west Turkey), Environmental Monitoring and Assessment, Cilt 184, s. 5453-5470. DOI: 10.1007/s10661-011-2352-8

[12] Tunçel, A., Kincal, C., Berge, M.A., Ongar, A., Göktürkler, G., Koca, Y. 2019. Investigation of a landslide: a case study from Eğridere, İzmir, Turkey. International Earth Science Colloquium on the Aegean Region, IESCA-2019, 7-11 Ekim, İzmir, 187189.

[13] Göktürkler, G., Balkaya, Ç., Erhan, Z. 2008. Geophysical investigation of a landslide: The Altındağ landslide site, Izmir (western Turkey). Journal of Applied Geophysics, Cilt 65 (2), s. 84-96 DOI: 10.1016/j.jappgeo.2008.05.008

[14] Bekler, T., Ekinci, Y.L., Demirci, A., Erginal, A.E., Ertekin, C. 2011. Characterization of a Landslide using Seismic Refraction, Electrical Resistivity and Hydrometer Methods, Adatepe - Canakkale, NW Turkey, Journal of Environmental and Engineering Geophysics, Cilt $16: 3$, s. 115-126. DOI: 10.2113/JEEG16.3.115

[15] Uyanık, O., Catlioglu, B. 2014. Elektrik Özdirenç ve Sismik Kırılma Yöntemlerinden Heyelan Geometrisinin Belirlenmesi. Süleyman Demirel Üniversitesi Fen Bilimleri Enstitü Dergisi, Cilt 18(3), s. 22-29.

[16] Erdoğan, B. 1990. İzmir-Ankara Zonu'nun İzmir ile Seferihisar Arasındaki Bölgede Stratigrafik Özellikleri ve Tektonik Evrimi: TPJP Bülteni, Cilt. 2:1, s. 1-20.

[17] Kıncal, C. 2004. İzmir İç Körfezi çevresinde yer alan birimlerin coğrafi bilgi sistemleri ve uzaktan algılama teknikleri kullanılarak mühendislik jeolojisi açısından değerlendirilmesi. Doktora Tezi, Dokuz Eylül Universitesi, Izmir.

[18] Turhanlar, B. 2015. Izmir İli Bornova Ilçesi Eğridere Mahallesi 1/5000 Ölçekli Nazim Imar Planina ve 1/1000 Ölçekli Uygulama Imar Planina Esas JeolojikJeoteknik Etüt Raporu, Izmir, Turkey (yayınlanmamış).

[19] Nakamura, Y. 1989. A method for dynamic characteristics estimation of subsurface using microtremor on the ground surface. QR of RTRI,Cilt 30, s. 25-33.

[20] Konno, K., Ohmachi T. (1998). Ground-motion characteristics estimated from spectral ratio between horizontal and vertical components of microtremor, Bulletin of the Seismological Society of America, Cilt 88, s. 228-241.

[21] SESAME (2004). Guidelines for the implementation of the $\mathrm{H} / \mathrm{V}$ spectral ratio technique on ambient vibrations-measurements, processing and interpretation. SESAME European Research Project Technical Report, European Commission Research General Directorate Project.

[22] Nakamura, Y. 2009. Basic Structure of QTS (HVSR) and Examples of Applications. In: Mucciarelli M., Herak M., Cassidy J. (eds) Increasing Seismic Safety by Combining Engineering Technologies and Seismological Data. NATO Science for Peace and Security Series C: Environmental Security. Springer, Dordrecht. DOI: 10.1007/978-1-4020-9196-4_4 
DEÜ FMD 24(70), 45-54, 2022

[23] Nakamura, Y. 1997. Seismic vulnerability indices for ground and struc- tures using microtremor. World Congress on Railway Research in Florence, Italy.

[24] Joyner, W.B., Fumal, T. 1984. Use of measured shearwave velocity for predictive geological site effects on strong motion. Proceedings of the Eighth World Conference on Earthquake Engineering, San Francisco, USA. 777-783.

[25] Midorikawa, S. 1987. Prediction ofisoseismal map in Kanto plain due to hypothetical earthquake. Journal of Structural and Construction Engineering, Cilt 33B, s. 43-48.

[26] Borcherdt, R.D. 1994. Estimates of site-dependent response spectra for design (methodology and justification). Earthquake Spectra, Cilt 10(4), s. 617654.

[27] Kanai, K., Tanaka, T., Yoshizawa, S. 1966. On Microtremors 9. Bulletin of the Earthquake Research Institute, University of Tokyo, Cilt 43, s. 577-588.

[28] Kramer, S.L. 1996. Geotechnical Earthquake Engineering, Prentice Hall, Upper Saddle River: 653 p.

[29] Tunçel, A., Pamukçu, O., Gönenç, T., Akgün, M. 2016. Mikrotremor, Çok Kanallı Yüzey Dalgaları (ÇKYD) ve Mikrogravite Yöntemleri Kullanılarak Zemin Dinamik Özelliklerinin İrdelenmesi: Karşıyaka-İzmir Örneği, Yerbilimleri, Cilt 37:2, s. 81-92. DOI: 10.17824/yrb.61207

[30] Nakamura, Y. 1997. Seismic vulnerability indices for ground and structures using microtremor, World Congress on Railway Research, Florence.

[31] Pamuk, E., Özdağ, Ö.C., Tunçel, A., Özyalın, S., Akgün, M. 2018. Local site effects evaluation for Aliağa/İzmir using HVSR (Nakamura technique) and MASW methods, Natural Hazards, Cilt 90, s.887-899. 